\title{
How to Prepare and Deliver a Scientific Presentation
}

\author{
Teaching Course Presentation at the 21st European Stroke Conference, Lisboa, May 2012
}

\author{
Andrei V. Alexandrov ${ }^{\mathrm{a}}$ Michael G. Hennerici ${ }^{\mathrm{b}}$ \\ ${ }^{a}$ Comprehensive Stroke Center, University of Alabama Hospital, Birmingham, Ala., USA; ${ }^{b}$ Department of Neurology, \\ UniversitätsMedizin Mannheim UMM, University of Heidelberg, Mannheim, Germany
}

\section{Key Words}

Science · Presentation · Quality

\begin{abstract}
Background: A scientific presentation is a professional way to share your observation, introduce a hypothesis, demonstrate and interpret the results of a study, or summarize what is learned or to be studied on the subject. Presentation Methods: Commonly, presentations at major conferences include podium (oral, platform), poster or lecture, and if selected one should be prepared to PRESENT: $\underline{P l a n}$ from the start (place integral parts of the presentation in logical

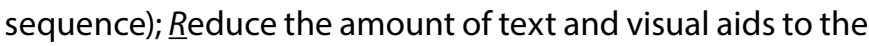
bare minimum; Elucidate (clarify) methods; Summarize results and key messages; Effectively deliver; Note all shortcomings, and Transform your own and the current thinking of others. We provide tips on how to achieve this. Presentation Results: After disclosing conflicts, if applicable, start with a brief summary of what is known and why it is required to investigate the subject. State the research question or the purpose of the lecture. For original presentations follow a structure: Introduction, Methods, Results, Conclusions. Invest a sufficient amount of time or poster space in describing the study methods. Clearly organize and deliver the results or synopsis of relevant studies. Include absolute numbers and simple statistics before showing advanced analyses. Remember to present one point at a time. Stay focused. Discuss study limitations. In a lecture or a podium
\end{abstract}

\section{KARGER}

Fax +4161306 1234

E-Mail karger@karger.com

www.karger.com
(C) 2013 S. Karger AG, Basel

$1015-9770 / 13 / 0353-0202 \$ 38.00 / 0$

Accessible online at:

www.karger.com/ced talk or when standing by your poster, always think clearly, have a logical plan, gain audience attention, make them interested in your subject, excite their own thinking about the problem, listen to questions and carefully weigh the evidence that would justify the punch-line. Conclusions: Rank scientific evidence in your presentation appropriately. What may seem obvious may turn erroneous or more complex. Rehearse your presentation before you deliver it at a conference. Challenge yourself to dry runs with your most critically thinking colleagues. When the time comes, ace it with a clear mind, precise execution and fund of knowledge.

Copyright $\odot 2013$ S. Karger AG, Basel

\section{Introduction}

Over time communication standards between scientists have evolved along with improved scientific method, increasing scrutiny of analyses and upholding to the highest level of evidence anything we call research. Scientific presentation is a professional way of sharing your observation, introducing a hypothesis, demonstrating and interpreting the results of a study, or summarizing what has been learned or is to be studied on the subject. Professional presentations help disseminate research, make peers aware of novel approaches, findings or problems. These presentations make conferences memorable for both presenters and the audience. Anyone can recall the most exciting and most boring, 
the most clear and most convoluted, the most 'seriously?!' and the most 'wow!!' presentations. Most presentations, however, fall in the in-between level of 'so what?', 'I did not quite get it ..., or 'maybe'. This means that all the work the authors have put in did not result in a paradigm shift, advancement, or even 'well, this is good to know' kind of an impact. We struggle to shape up our young presenters to make their science clear and visible, their presence known and their own networks grow.

Having initially struggled in preparing and delivering presentations ourselves, and having seen the many baby steps of our trainees now accomplished or shy of a track record, we have put together these suggestions on how to start, organize and accomplish what at first sight looks like a daunting task: presenting in front of people, many of whom may have expertise way beyond your own or who are scrutinizing every bit of data and ready to shred any evidence you might have to pieces. Unfortunately, there is no other way to advance science and become recognized than to survive this campaign from conception of a project to publication. This campaign has its own (often interim and hopefully not singular) culmination in a scientific presentation. This presentation also comes with question and answer sessions and importantly, with you and the audience possibly coming out of it with new messages, new thinking and even energy for breakthroughs, no matter how small or large the leap would be. So let's explore how to prepare and deliver a scientific presentation.

\section{Presentation Methods}

Currently, the common types of presentations at major conferences include podium (oral, platform), poster or lecture. Although seemingly different and at times some being more desirable over others, they all share the same prerequisites and challenges for successful execution. We will examine common threads and identify unique aspects of each type of these presentations. However, the first prerequisite for any scientific presentation (successful or not) is you, the presenter.

An effective presenter should have led the study, participated in the analysis and drafting of the abstract and manuscript, i.e. the presenter should know the subject of his or her talk inside out. One should therefore be prepared to PRESENT:

Plan from the start (place integral parts of the presentation in logical sequence);

How To Prepare and Deliver a Scientific Presentation
Reduce the amount of text and visual aids to the bare minimum;

Elucidate (clarify) methods;

Summarize results and key messages;

Effectively deliver;

Note all shortcomings, and

Transform your own and the current thinking of others.

So, as the scuba-diving instructors say: plan the dive, and dive the plan. The most important parts of scientific presentations should follow the logic of delivering the key messages. For the original presentations (platforms or posters), it is easy to simply follow the accepted abstracts, most often structured following the IMRaD principle: Introduction, Methods, Results and Discussion (Conclusions).

Lecture format, content and logical flow of information often depend on the topic choice, which should be appropriate to the level of audience [1], time allotment and the target audience. Most competitive conferences offer short times even for invited lecturers as experts are expected to demonstrate cutting edge science, which assumes that the audience is already knowledgeable and the expert is capable of delivering information that sparks new thinking. The suggestion here to both novice and experienced speakers is to quickly summarize why the subject of presentation is important (catch audience attention [2,3]), where we are now (show the landscape of completed studies that established the common knowledge or conundrums, equipoise, etc.) and to move then to the latest advancements (this may include just-in publications, ongoing or planned future research or the most provocative take on the evidence out there).

Turning back to original presentations, advice is available on how to write abstracts following the IMRaD principle [4] and how to draft subsequent manuscripts [5]. We cannot stress enough the need to quickly follow-up the abstract submission with drafting the full manuscript. If the authors complete a manuscript before the presentation at a conference, the presenter will have a luxury of material to work with to compile either a set of slides for the podium or text and illustrations for the poster. If a manuscript was drafted and reviewed by coauthors, the challenge for a presenter is going to be a good one: trim down most sentences as both slides and posters benefit from short statements (not even full sentences) and large font sizes so that text can be easily read from a distance. Put yourself into the audience: your slides should be readable from the last row of a large room or a huge ballroom and your poster should be still readable from at least $2 \mathrm{~m}$.

Cerebrovasc Dis 2013;35:202-208 
The latter will allow better poster viewing by several people during guided poster tours or when a small group gathers spontaneously to view it.

This logically brings us to the second step: use bare minimum of any type of information to deliver your presentation. Minimum text, minimum lines, minimum images, graphs, i.e. provide only the essential information as the audience attention span is short. Brevity, however, should not compromise quality: you should always stride to have the highest quality visual aids since these leave an impression on the audience [6] and good quality graphics are attributes of effective presentations [3].

At the same time, we cannot overemphasize the need to stick to time limits set for a specific presentation. Presenters should test their presentation in 'real life' at home to their friends or at work in front of colleagues and ask for criticism. It is better to get criticism from members of the department (including your boss) than in a huge auditorium. Use a simple rule: an average talking time is 1 min per slide in oral presentations. You can then see how little you really can allocate to each slide if you load your talk with the most complicated visual presentation of data.

Let's go to the specifics. The 'Introduction' slide usually includes a very brief description of background and should explicitly state the research question. Call it 'Introduction and Study Purpose'. Adding a separate slide for study aims lengthens the talk. Fewer slides also reduce the chance of making an error when advancing them on the podium that can send presenters into further time deficit and stress, a commonplace even with those who know how to right-click.

Methods should have bullet points, not necessarily full sentences since you will be speaking over slides projecting or in front of the poster to connect brief statements showing behind you. The basic rule is not to read your slides or poster, nor tell the audience to read what the slide or poster says. Think of your slides or display material as a reminder to yourself of what you are supposed to say in detail and leave the noncritical words out of the slide and off the poster as it is an even easier source to pack with unreadable information. When you develop a presentation imagine you are a novice to the field who would like to be educated and taken on a journey while seeing and hearing the presentation. What can I learn in these few minutes? As the presenter, also think 'what can I pass to the audience in these few minutes?' Further advice on how to plan, focus and arrange material to support key messages is available $[7,8]$.
Results are the key part of any scientific presentation, podium, poster or lecture, and the most time, space and careful ascertainment should be allotted to this section as is necessary and feasible. It is vital to pack your presentation with data that support your key messages. Remember, a picture is worth a thousand words but show only quint-essential images or graphs. If appropriate include statistics and make this easy in structure, i.e. use formats or values known by everybody such as odds ratios, Kaplan Meier curves, etc. (do not forget to include these data in the abstract as abstracts without data, numbers and calculations are often low rated or rejected). After presenting data, show what you think of that or what the limitations are since you thought more about this than the audience, at least through preparation of your own presentation.

The last two concluding paragraphs (poster), comments (this section of a lecture), or slides (podium) are supposed to cover study limitations and conclusions. These should be the most carefully thought through, strategically worded and evidence-based part of your presentation. Your reputation depends on the quality of data interpretation. Also, think about a take-home message with the main message you want to be remembered. When practicing your presentations, deliver your talk to your nonmedical spouse, boyfriend or girlfriend: by the end of your presentation he or she should be able to repeat the take home message with best-prepared presentations.

After conclusions, an 'Acknowledgements' slide is nice to have at the end showing whom you are grateful to, but it will not rescue a hopeless presentation. The 'thanks to my colleagues' should not come at the expense of time, quality and content of your scientific presentation. There is no need to thank multiple people like they often do at the Oscars. You have to rationally consider who and when to acknowledge if their functions were important to your work but they were not listed among coauthors. If you received funding to support your work, it is very important where appropriate or at the end of the presentation to acknowledge your sponsors or grant providers (such as NIH Institute and grant number, MRC grant, INSERM or DFG labels, etc.). The higher the scientific level of the grant donors, the more your presentation will be recognized.

While preparing any part of your presentation, remind yourself to check whether the included material is any good and worthy of inclusion. You can simply ask, 'am I wasting time during the oral presentation or space in the poster by including this and that?' The answer lies 
Table 1. Basic structure for a podium presentation of an original paper

\begin{tabular}{|c|c|}
\hline Slide & Comment \\
\hline 1. Title slide & $\begin{array}{l}\text { List the full title of your project, last names and } \\
\text { initials of all listed coauthors and affiliation(s). }\end{array}$ \\
\hline 2. Conflicts & $\begin{array}{l}\text { Most competitive conferences now require } \\
\text { disclosure or conflicts such as unapproved/ } \\
\text { off-label use and personal conflicts of interest } \\
\text { in regards to the research subject - follow tem- } \\
\text { plates that organizers usually provide. }\end{array}$ \\
\hline 3. Introduction & $\begin{array}{l}\text { Brief bullet points about background. } \\
\text { State clearly the aim of the study or research } \\
\text { question. }\end{array}$ \\
\hline 4. Methods & $\begin{array}{l}\text { One-line, brief bullet points. } \\
\text { No more than } 10 \text { lines per slide (the fewer the } \\
\text { better - this enlarges font size); add more } \\
\text { slides if necessary. }\end{array}$ \\
\hline 5. Results & $\begin{array}{l}\text { Brief lines of numeric data. } \\
\text { No more than } 10 \text { lines per slide. } \\
\text { Use graphs or images with high resolution and } \\
\text { large axis value/numbers; add more slides if } \\
\text { necessary. }\end{array}$ \\
\hline $\begin{array}{l}\text { 6. Study } \\
\text { limitations }\end{array}$ & $\begin{array}{l}\text { Mention these instead of a general 'Discussion' } \\
\text { slide - most critical questions after the talk } \\
\text { point to study limitations - so be open about } \\
\text { them to avoid negative discussion after the } \\
\text { presentation. }\end{array}$ \\
\hline 7. Conclusions & $\begin{array}{l}\text { Brief statements outlining the most important } \\
\text { key messages. }\end{array}$ \\
\hline $\begin{array}{l}\text { 8. Acknowledge- } \\
\text { ments }\end{array}$ & $\begin{array}{l}\text { - Include this slide if you need to thank funding } \\
\text { agencies and sources as well as people who } \\
\text { were not listed as coauthors. If you wish to } \\
\text { thank someone among coauthors, do so briefly } \\
\text { while showing the title slide. }\end{array}$ \\
\hline
\end{tabular}

in checking if this material is directly related to the study aim, data obtained, or in support of conclusions drawn.

Table 1 summarizes how you should structure the sequence of slides for the podium presentation. If you are only given $8 \mathrm{~min}$ to present $+2 \mathrm{~min}$ for questions (10 $\mathrm{min}$ total), you can see that with 8 mandatory slides you are already at the limit of $1 \mathrm{~min}$ per slide. In due course, we will give you tips on how to reallocate time within your presentation to expand the Methods and, most importantly, the Results section as needed.

Always clarify study methods. Posters offer a greater freedom since you can show details of your experimental setup or the methodology of your study design. A podium presentation often requires abbreviated mention of key elements of design, scales, inclusion/exclusion crite- ria, intervention or dependent variables and outcomes. This requires diligent work with your coauthors and biostatisticians to make sure that you are brief but clear and sufficient.

A well-assembled Methods section will lead to a shorter Results summary since your clear statement of the study aim and key methodology logically leads to audience anticipation of the primary end-point findings. There are key messages and delivered data points that distinguish effective and clear presentations from those resulting in confusion and further guesswork.

\section{Delivering a Presentation}

Effective presenters capture audience attention and stay focused on key messages [1-3, 6-8]. A study was performed at scientific conferences asking reviewers to identify the best features of effective presentations [3]. The most frequent comments on best features of presentations with respect to 'content' were identifying a key concept (43\% of presentations) and relevance ( $43 \%)$. Best features in evaluations of 'slides' were clarity (50\%), graphics (27.3\%) and readability of the text and font size (23\%). Finally, best features in 'presentation style' were clarity (59\%), pace (52\%), voice (48\%), engaging with the audience (43\%), addressing questions (34\%) and eye contact (28\%) [3].

Here are some tips on how to avoid forcing yourself to rush during a talk. Before you start (usually in the intermission or just before your session) familiarize yourself with the podium and learn how to advance slides and operate the pointer or point with the mouse. If you stumble at the beginning, you start your presentation with a time deficit.

Get to the podium while you are being introduced and start right away (it is the responsibility of the moderator to properly announce you, your team and the title of the talk and it is the responsibility of the conference organizers to have your title slide showing during the moderator's announcement). Do not read or repeat your study title. Thank the moderators and while the title slide is showing you may consider briefly thanking your coauthors/mentor here in just a few seconds.

Show the 'Conflicts of Interest' slide next and disclose if any conflicts are related to the study subject. If they exist, conflicts should be acknowledged briefly but clearly. Do not show a slide with several conflicts and tell the audience 'here are my conflicts' and switch to the next slide. It is important to simply say, 'pertinent to this study I have 
...' or 'this study includes an off-label or investigational use of ..... Now you are logically ready to turn to the subject of your presentation.

Start with a brief summary of what is known and why is it important to investigate the subject. This introduces the audience to the subject of research and starts the flow of logic. If you are facing a challenge to present a complex study within in a short allotted period of time (such as $8 \mathrm{~min}$ for podium or a just a few minutes during a guided poster tour), do not waste time. You may cut to the chase and simply say why you did the study. Coming with straight forward messages, which are authentic and concerned about the scientific question, gets you more credit with the audience than careful orchestration of a perceived equipoise. However, we have digressed.

For an effective message delivery, identify two people towards opposite far ends of the audience and speak as if you are personally talking to one of them at a time and alternate between them. If lights shining in your face are too bright, still look towards the back of the room (or from time to time directly into the camera if your talk is being shown on monitors in a large ballroom) and do not bury your head into the podium or notes that you might have brought with you. The nonverbal part of any presentation and the presenter's body language are also important [6]. At all cost avoid bringing notes with you to any scientific presentation since you should have practiced your talk enough to remember it or you should be familiar with the subject of your lecture to the point that even if you have just been woken up, you can still maintain an intelligent conversation. Do not count on 'it will come to me' - practice your talk! Further advice on effective presenting skill is available [2].

Remember that at international conferences many attendees are not native English-speaking people. Thus speak slowly and train your voice for best possible pronunciation! This recommendation is applicable to natives of English-speaking countries too. Native English speakers from the UK, Commonwealth countries and the USA tend to speak fast, with a variety of accents that international audiences may not understand easily while the interpreters may not be able to keep up. When speaking, do not turn away from the audience and look at your slide projection on the main screen or at your poster all the time. If it is necessary to remind yourself what to talk about next, advance the slide, briefly glance at it, turn to the audience and continue your presentation. Turn to your slide again only if you have to use a laser pointer or a mouse on the computer screen. Do so briefly, underline the important finding, point to the key part of an image and avoid long circular pointer motions around the whole text line or big areas of graphic illustrations. It is distracting. Try to use the pointer only when necessary and do not read your slides with the pointer constantly aiming at where you are reading.

When presenting your methods, clearly state the type of study, e.g. retrospective analysis, case series, cohort or controlled trials, etc., and describe patient inclusion/exclusion criteria. If too numerous, only list the major ones. As an example, in a clinical trial of a fibrinolytic agent the list of exclusion criteria could be very extensive, so how can you present this on a dime? Your slide should focus on the key inclusion criteria since a patient who did not have those was obviously excluded, and an audience at a stroke conference is generally familiar with multiple exclusion criteria for tissue plasminogen activator treatment. So, your slide or poster may have the following in it (highlighted in bold) to which you may add the plain text in your (limited) verbal statements:

\section{Study Methods}

Our Major Inclusion Criteria: were

- total Pre-treatment NIHSS score $>\mathbf{6}$ points

- Presence of mismatch on MRI determined by (EPTITHET) trial criteria

- Age $<80$ years and

\section{- Time from symptom onset $<\mathbf{8} \mathrm{h}$}

After that, you may omit including a slide with the long list of exclusions in favor of time. If there is a specific contraindication new to the treatment agent in your study, you could say in addition to well-known contraindications for systemic thrombolysis, patients were excluded if they had ...' at the end of showing the 'Major Inclusion Criteria' slide as shown above. Similarly, in a poster, list only the most relevant inclusion and exclusion criteria and walk the audience through the methods without stumbling on too many detail disclosures. The audience will lose track of where you are going.

It is important to keep a balance between sufficient disclosure of study methods and the length of this part of your presentation. It is always helpful if you have a prior study that used a similar or from which you developed your methodology that has already been published - you may show a reference to this study and move on faster without sacrificing the quality. For example, 'ultrasound 
tests were done by experienced sonographers using a previously published standard protocol', 'CT scans were read independently using the ASPECTS score', and 'sICH was defined by the SITS-MOST criteria'. Say this while showing or pointing to the line and published source reference on your visual aid.

Clearly organize and deliver the Results section. Include absolute numbers and simple statistics before showing advanced analyses. Remember not to show data in Methods and equally so do not introduce new methods when presenting Results. As a rule, describe characteristics of the general study population or balance/imbalances between target and control groups. Follow this by a slide that shows the primary end-point findings or observations that directly address the study aim or research question. This follows the logic of a scientific presentation and will help you avoid deviations to side observations no matter how unexpected or valuable they seem. Stay the course, address the main question first and only then show additional findings. When presenting a poster, point to the area where the key results are displayed. Unlike a slide presentation or lecture where the audience is forced to see one slide at a time, busy posters could be distracting. Posters that are heavily packed with graphs, images, tables and text are often difficult to follow during a brief guided poster presentation tour. It is the presenter's responsibility to drive the audience attention to key results in a logical sequence. When you present a graph, start by telling the audience what is shown and in what units on each access, and briefly point to the numbers on each axis.

Remember to present one point at a time. It makes common sense but sometimes may be difficult to follow if complex experiments or studies with multiple confounding variables have to be navigated through a brief presentation. Do not lose sight of your original research question or the objective of your lecture. Remember what you have shown so far, and what logically should be shown next. If you are pressed on time or made a mistake while advancing slides, take a deep breath and relax. Clear state of mind will buy you time. Racing thoughts such as 'I have to cover that and that, and oh, that too' are not helpful. Dry runs, or practice presentations are essential for you to master the material that you need to present.

After finishing the Results part of your presentation, remember not to introduce more new results in Discussion and Conclusions. That surprise is hard for the audience to process. If you'd like to reemphasize the main finding, use the following suggestion. Let's say your goal was to show the prevalence of a new syndrome in your study population and you found it to be $24 \%$ (your primary research question). Unexpectedly, you also found that patients with this syndrome have an increased risk of dying (RR 2.08, 95\% CI 1.23-4.34). These numbers and statistics obviously belong to the Results section. However, you want to stress in your conclusion once again how important your finding is. You can present it as follows: 'Conclusions: nearly a quarter of stroke patients can be affected by this new syndrome and, if present, it doubles the patient chance of dying in hospital'. This recaps the main finding and makes practical interpretation of the relative risk estimate.

Before you jump into Conclusions, however, we always encourage presenters to note and openly discuss current study limitations. This improves your own assessment for biases and ranking of the level of obtained evidence. If you do not disclose the obvious study limitations, you will most likely receive questions after your presentation that will point to these shortcomings. Thus, instead of a positive discussion of how your study advances our knowledge, the discussion with the audience will focus on shortcomings and the key message may be lost with the negative audience response. Unlike Twitter ${ }^{\mathrm{TM}}$ or future media-based quick popularity scores, science can only advance when it endures the highest scrutiny (even though in the future presenters may be concurrently judged by the audience as our technologies improve). Regardless, if you are a good scientist, prepare yourself to stand the ground if the evidence is behind you. Be proactive, acknowledge study limitations and how you attempted to control for biases, etc.

In a lecture or a podium talk or when standing by your poster, always think clearly, have a logical plan for presentation parts that should be covered next, gain audience attention, make them interested in your subject, excite their own thinking about the problem, listen to questions and carefully weigh the evidence that would justify the punch-line. This will support your conclusions!

With posters, we often see a Discussion section but no conclusions listed, or they are listed in the abstract but not in the poster itself. This will lead to an obvious question after you stop presenting: 'So, what is your take on this?' Our advice is, have your conclusions listed and be prepared to defend them point-by-point as the question and answer part could be challenging. If you do not understand the question, ask for clarification rather than talk nonsense. 


\section{Discussion: Transform!}

To arrive at the right conclusions, you have to rank scientific evidence in your presentation appropriately. What may seem obvious may turn erroneous or more complex at a closer look by experts. Helpful hints here include you maintaining careful documentation while you are conceiving the project, designing it with your colleagues and consulting with a biostatistician on all steps taken in ascertaining the study population, interventions, end-point data collection and bias verification. Put all methodological issues against your findings and this will give you an idea of the strengths and weaknesses of your study. Preparing and delivering your presentation is a great experience to see if your knowledge and gained expertise stand up to peer scrutiny.

Rehearse your presentation before you deliver it at a conference. Challenge yourself to dry runs with your most critically thinking colleagues. Quite often, it is not the presentation itself but these questions, comments and subsequent late night debates with your colleagues that bring new thinking, advance our understanding and spark new ideas. This is the chance to transform your own current thinking and that of your peers. Think about your upcoming presentation, whether it is a podium, poster or lecture, as an opportunity, a launch pad, a reward for the hard work you did to bring this project to the attention of the scientific community.

When time comes, ace it with a clear mind, precise execution and fund of knowledge.

\section{Acknowledgements}

Before his first oral presentation in English, Dr. Alexandrov was nervous and asked his mentor, Dr. John W. Norris, for a dry run. Dr. Norris generously came to listen to him at 10 p.m. the night before, and Dr. Alexandrov survived his talk.

\section{References}

$>1$ Spinler SA: How to prepare and deliver pharmacy presentations. Am J Hosp Pharm 1991; 48:1730-1738.

$>2$ Garon JE: Presentation skills for the reluctant speaker. Clin Lab Manage Rev 1999;13: 372-385.

-3 Estrada CA, Patel SR, Talente G, Kraemer S: The 10-minute oral presentation: what should I focus on? Am J Med Sci 2005;329: 306-309.
-4 Alexandrov AV, Hennerici MG: Writing good abstracts. Cerebrovascular Dis 2007; 23:256-259.

7 Alexandrov AV: How to write a research paper. Cerebrovascular Dis 2004;18:135-138.
6 Mayer K: Fundamentals of surgical research course: research presentations. J Surg Res 2005;128:174-177.

77 Thompson WM, Mitchell RL, Halvorsen RA Jr, Foster WL Jr, Roberts L: Scientific presentations: what to do and what not to do. Invest Radiol 1987;22:244-245.

$>8$ Collins J: Education techniques for lifelong learning: giving a PowerPoint presentation: the art of communicating effectively. Radiographics 2004;24:1185-1192. 